\title{
TITLE: NASOGASTRIC TUBES AFTER CARDIAC SURGERY: IMPACT ON NAUSEA AND VOMITING
}

AUTHORS: Yuji Hirasaki, MD, Hyunju Jung, MD, Leonid Minkovich, MD, Rita Katznelson MD, Humara Poonawala MD, Andrew Cheng, Linda Jussaume, RN, Jo Carroll, $\mathrm{RN}$, George Djaiani, MD

AFFILIATION: Department of Anesthesia \& Pain Management, Toronto General Hospital, University Health Network, University of Toronto, 200 Elizabeth Street, Toronto, ON, M5G 2C4

BACKGROUND: Incidence of postoperative nausea and vomiting (PONV) after cardiac surgery is $30-40 \%$. The role of nasogastric tube (NGT) in reduction of PONV is still controversial. OBJECTIVES: The purpose of this study is to assess the impact of NGT placement on PONV in patients undergoing cardiac surgery.

METHODS: After REB approval and informed consent, 114 patients undergoing cardiac surgery with cardiopulmonary bypass were randomized to either receive NGT after induction of anesthesia (Group NGT) or to the control group (no NGT). Patients with history of gastro/duodenal ulcer, gastric/esophageal surgery, and/or history of antiemetic treatment were excluded. Standard fast-track cardiac anesthesia and postoperative care were employed for all patients. Incidence of PONV was recorded hourly for first 4 hours after extubation and every 4hours afterwards for 24hours. Usage of antiemetics and pain medication were also recorded. Data were analyzed with t-test and chi-square test for continuous variables and categorical data, respectively. $\mathrm{P}<0.05$ was considered statistically significant.

RESULTS: The groups were similar with respect to demographic data, surgical characteristics, and opioid usage. There was no significant difference in the incidence of PONV and the antiemetic usage between the two groups (Table).

\begin{tabular}{|l|c|c|c|}
\hline Table & Group NGT $(\mathrm{n}=53)$ & Controls $(\mathrm{n}=61)$ & P value \\
\hline Gender (male / female) & $43 / 13$ & $45 / 16$ & NS \\
\hline Age (yr) & $58 \pm 12$ & $55 \pm 11$ & NS \\
\hline Nausea within 24 hrs, $\mathrm{n} \mathrm{( \% )}$ & $17(32 \%)$ & $21(34 \%)$ & NS \\
\hline Vomiting within 24hrs, $\mathrm{n}(\%)$ & $8(15 \%)$ & $12(19 \%)$ & NS \\
\hline Required antiemetics, $\mathrm{n}(\%)$ & $17(30 \%)$ & $20(32 \%)$ & NS \\
\hline
\end{tabular}

Mean \pm standard deviation, $\mathrm{n}$ : number of patients, NS: not significant.

DISCUSSION: This study showed that placement of NGT did not impact on the incidence of PONV or requirements for antiemetics after cardiac surgery. The results of this study do not support the routine use of NGT to reduce PONV after cardiac surgery. 